\title{
Synthesis of CdS Nanoparticles by Electrochemical Method: Correlation for Photodegradation of Trichloroacetic Acid, Chloroacetic Acid, Acetic Acid and Antibacterial Efficiency
}

\author{
Rajegowda Shilpa ${ }^{1}$, H.C. Charan Kumar ${ }^{1}$, Sanniaha Ananda ${ }^{2, *}$ \\ ${ }^{1}$ Departrment of chemistry Manasagangotri, UOM, Mysuru - 570 006, Karnataka, India. \\ ${ }^{2}$ Department of chemistry, UGC-BSR Faculty, Manasagangotri, UOM, Mysuru - 570 006, Karnataka, India.
}

\section{A R T I C L E D E T A I L S}

\section{Article history:}

Received 21 January 2020

Accepted 02 March 2020

Available online 05 May 2020

\section{Keywords:}

Electrochemical Method

CdS Nanoparticles

Carboxylic Acids

LFER

Antibacterial Activity

\begin{abstract}
A B S T R A C T
Cadmium sulfide (CdS) nanoparticle has been successfully synthesized by electrochemical method which is simple and inexpensive method. The synthesized CdS nanoparticles were used as a catalyst for the photodegradation of trichloroacetic acid, chloroacetic acid and acetic acid under various experimental conditions by volumetric method. The CdS nanoparticles were characterized by various techniques such as SEM-EDAX, UV-Visible spectroscopy, FTIR-IR spectrum and X-ray diffraction studies. The study of UV-Visible spectroscopy revealed that the CdS nanoparticles showed that the maximum intensity peak at $253.64 \mathrm{~nm}$ in the UV-region and the band gap energy is found to be $2.39 \mathrm{~nm}$ which was calculated using Tauc-plot. The SEM results showed that the CdS nanoparticles have spherical shape. The EDAX spectra revels the presence of $\mathrm{Cd}$ and $\mathrm{S}$ in the nanoparticles. From XRD data, the structure of CdS nanoparticles was found to be cubic structure and crystallite size was found to be $16.10 \mathrm{~nm}$. The photocatalytic activity of the synthesized CdS nanoparticles was investigated by the kinetics of photodegradation of carboxylic acids by volumetric method by using $\mathrm{NaOH}$ solution. Taft LFER was tested, the isokinetic temperature $\beta$ was calculated for oxidation of carboxylic acids. The antibacterial activity of CdS nanoparticles was investigated by using gram positive (Bacillus subtilis MTCC 2763) and gram negative (Escherichia coli MTCC 40) bacteria by disc diffusion Kirby-Bauer method in Mueller Hinton Agar Plate by determining the ZOI.
\end{abstract}

\section{Introduction}

In the recent days nanomaterials has become one of the encouraging tools for experimental modification. Metal nanoparticles have found many applications in electronics, medicine, and in many industries because of their electronic, unique, catalytic, optical, and magnetic properties. Catalysis using metal sulfide nanomaterials is great activity being carried out to assure the biological applications [1-5]. Nanomaterials are the most intense research subject of material scientists due to their good physical and chemical properties. Electrochemical methods were proven to have some additional advantages over chemical methods in the synthesis of various nanomaterials, especially metal nanocomposites [6-8]. CdS is one of the most important compounds of group II-VI semiconductors with physical and electrochemical properties and a direct band gap of $2.39 \mathrm{eV}$. CdS has been used in optoelectronics, photoluminescence, and photocatalysis $[9,10]$. The different methods have been developed to synthesize the CdS nanomaterials with different morphologies and structures such as quasi-nanospheres, nanocrystals, nanorods, nanobelts, nanowires, and nanotubes. One-dimensional semiconductor nanostructures have drawn intensive interest due to their fundamental research and potential applications in fabrication of nanoscale devices [11-13]. CdS nanomaterials have been considerable attention due to their exclusive properties, which are not present in bulk materials [14]. CdS is an n-type semiconductor used as sensitizers in quantum dot sensitized solar cells [15-18]. In the present study CdS nanoparticles have been synthesized by electrochemical method which is an environmentally friendly method. The synthesized CdS nanoparticles were used as a photocatalyst for the degradation of carboxylic acids by volumetric method by using $\mathrm{NaOH}$ solution and the degradation kinetics of carboxylic acids were studied.

\section{Experimental Methods}

All chemicals were used to prepare CdS nanoparticles were the analytical grades of purity. Cd electrode was purchased from Alfa Aesar. Trichloroacetic acid, chloroacetic acid and acetic acid were purchased from Lobachemie and platinum electrode from Elico Pvt. Ltd. All solutions were prepared using double distilled water. The optical properties for prepared CdS nanoparticles were studied by UV-visible spectrophotometer (shimadzu-1700 series). The X-ray crystallographic interpretations were performed by X-ray diffractometer (Panalytical Xpert) using $\mathrm{Cu}$ Ka wavelength $(\lambda=1.54)$ scanning range from 0 to $70 \AA$. The morphological feature for the prepared CdS study was determined by scanning electron microscopy (SEM-EDEX) using Quanta-200 FEI, Netherlands. The elemental analysis for the conformation of prepared $\mathrm{Cd}$ and $\mathrm{S}$ is confirmed from energy dispersive $\mathrm{X}$-ray analysis (EDAX).

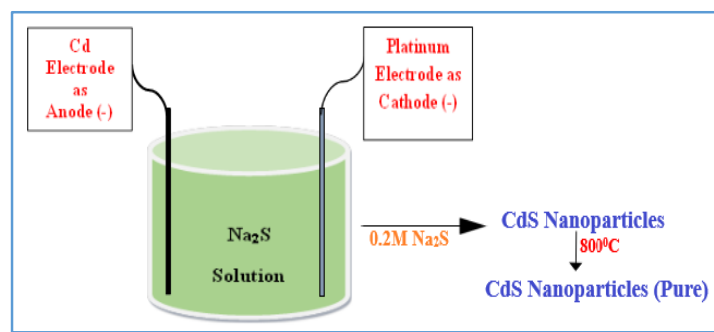

Fig. 1 Experimental set up for the electrochemical synthesis of CdS nanoparticles

\subsection{Synthesis of CdS Nanoparticles by Electrochemical Method}

The CdS nanoparticles were synthesized by electrochemical method by using Cd electrode in an aqueous system with $\mathrm{Na}_{2} \mathrm{~S}$ as a conductive salt. The $\mathrm{Na}_{2} \mathrm{~S}$ act as the sulphur source. The $\mathrm{Cd}$ metal electrode is used as anode and platinum electrode is used as cathode using $20 \mathrm{~mA}$ current and potential of $10 \mathrm{~V}$ the experiment was run for $2 \mathrm{~h}$ with continues stirring. The electrolytic cell is consisting of $0.2 \mathrm{M}$ of $\mathrm{Na}_{2} \mathrm{~S}$ solution. The distance of the anode and cathode during electrolysis was $2 \mathrm{~cm}$. The electrochemically generated $\mathrm{S}^{2-}$ species reacted with $\mathrm{Cd}^{2+}$ in the electrolyte to produce $\mathrm{CdS}$ 
nanoparticles. The experimental set up is as shown in Fig. 1. The obtained solid CdS is washed with double distilled water till complete removal of unreacted $\mathrm{Na}_{2} \mathrm{~S}$. The solid $\mathrm{CdS}$ is centrifuged and calcined for $2 \mathrm{~h}$ at $800{ }^{\circ} \mathrm{C}$ for dehydration and for the removal of $\mathrm{Na}$ and $\mathrm{OH}$ impurities which has formed in electrolysis and atmospheric oxidation. The reaction flow for the synthesized CdS nanomaterial is given as,

$\begin{array}{lll}\mathrm{Cd} & \leftrightarrow & \mathrm{Cd}^{2+}+2 \mathrm{e}^{-} \\ \mathrm{Na}_{2} \mathrm{~S} & \leftrightarrow & 2 \mathrm{NaOH}+\mathrm{S}^{2-} \\ \mathrm{Cd}^{2+}+\mathrm{S}^{2-} & \leftrightarrow & \mathrm{CdS}\end{array}$

\subsection{Determination of Photodegradation Kinetics by Volumetric Method}

Volumetric titration is widely used in quantitative analytical method. This method involves the measurement of volume of a solution of known concentration which is used to determine the concentration of the analyte. In the present work the volumetric titration method was used to determine the degradation efficiency, by measuring the concentration of carboxylic acid by the titration against $\mathrm{NaOH}$ solution at different time intervals. After complete degradation of carboxylic acid pink colour formation takes place with phenolphthalein without adding $\mathrm{NaOH}$ solution. A plot of $\log \mathrm{V} / \mathrm{V}_{0}$ versus time was linear up to $60 \%$ of the reaction illustrate the appearance of carboxylic acid follows $1^{\text {st }}$ order kinetics. The different concentration of carboxylic acid solutions $\left(0.5 \times 10^{-3}\right.$ to $\left.3 \times 10^{-3} \mathrm{~N}\right)$ were prepared by dissolving in distilled water. This solution was used as a test contaminant for evaluating photocatalytic activities of the prepared CdS nanoparticles. The experiment was carried out under tungstenhalogen UV-light in order to check the effect of CdS nanoparticles. The COD values were investigated for both before and after degradation of all the carboxylic acid solutions using dichromate oxidation method $[19,20]$. COD effect was calculated by the following equation.

COD $=($ Blank - Sample $) \times N_{F A S} \times 8000 / V_{\text {sample }}$

\section{Result and Discussion}

\subsection{UV-Visible Spectra}

It is confirmed that from the optical absorption spectra, the absorption band of the CdS nanoparticles had been showing a blue shift which is due to particle size in nano region [21,22]. Fig. 2 shows that the synthesized CdS nanoparticles has maximum intensity peak at $253.64 \mathrm{~nm}$ in the UVregion and there is no absorption peak in the visible region, Further, the rate of degradation of carboxylic acids in presence of sunlight is very slow compare to UV light. The UV-Visible spectrum of CdS nanoparticles over the range 200-700 $\mathrm{nm}$ showed that the synthesized nanoparticles are photoactive under ultraviolet radiation. The band gap energy of synthesized CdS nanoparticles was calculated using Tauc plot $[23,24]$ by plotting $(\alpha \mathrm{hm})^{1 / 2}$ verses $\mathrm{h} \gamma$, and it is found to be $2.39 \mathrm{eV}$.
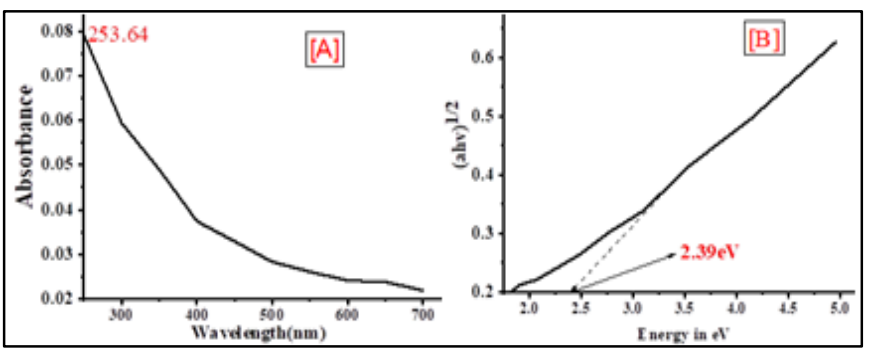

Fig. 2 UV-Visible spectra (A) and Tauc plot (B) of CdS nanoparticles

\subsection{X-Ray Diffraction}

Fig. 3 shows the XRD pattern of synthesized CdS nanoparticles.The obtained peaks indicates the presence of mixed phases of CdS. The positions of the peak appearing at 2 theta values are 18.40, 26.07, 30.59, 31.37 and 52.62 which could be indexed as (100), (002), (222), (310) and (201) crystal plans of the CdS nanoparticles. All these diffraction peaks can be perfectly matched with respect to their position with cubic crystal structure. By using Debye-scherrers equation $D=k \lambda / \beta \cos \theta$, the average crystal size of the synthesized CdS nanoparticles were calculated and it is found to be $16.10 \mathrm{~nm}$ [25] where $\mathrm{k}$ is an empirical constant equal to $0.9, \lambda$ is the wavelength of the X-ray source, $\beta$ is the full width at half maximum of the diffraction peak and $\theta$ is the angular position of the peak. With reference to the JCPDS card \#41-1049 standards [26], the peak at $18.40^{\circ}$ reflects $(100)$ planes, $26.07^{\circ}$ reflects $(002)$ planes, $30.59^{\circ}$ reflects $(222)$ planes, $31.37^{\circ}$ reflects (310) planes and $52.62^{\circ}$ reflects (201) planes. Hence XRD analysis clearly indicates the presence of CdS nanoparticles. https://doi.org/10.30799/jnst.294.20060104

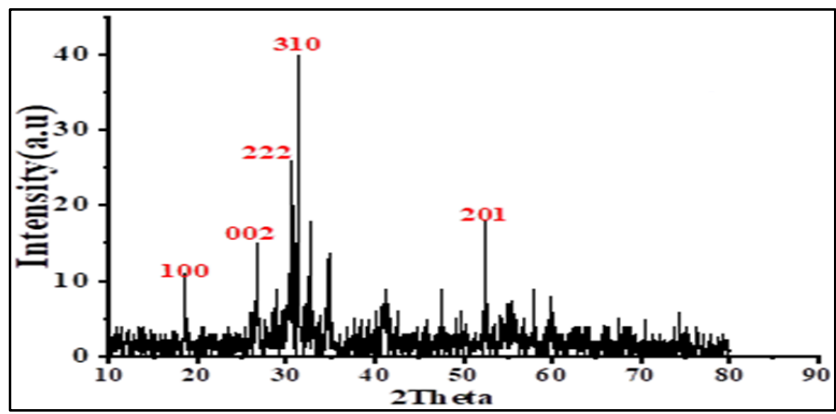

Fig. 3 XRD pattern of CdS nanoparticles

\subsection{Scanning Electron Microscopy (SEM)}

SEM is high-resolution microscopy which provids detalied surface data of solid samples which include morphological and copositional information. The CdS nanoparticles are nanoflake structure when observed at different magnification. From the Fig. 4, it is clear that the particles were agglomerated in nature. The SEM image shows randomly distrubuted CdS grains with smaller size. The EDAX spectrum conformed the presence of $\mathrm{Cd}$ and $\mathrm{S}$ in the nanomaterial. The atomic percentage composition of the elements $\mathrm{Cd}$ and $\mathrm{S}$ were observed to be equal.

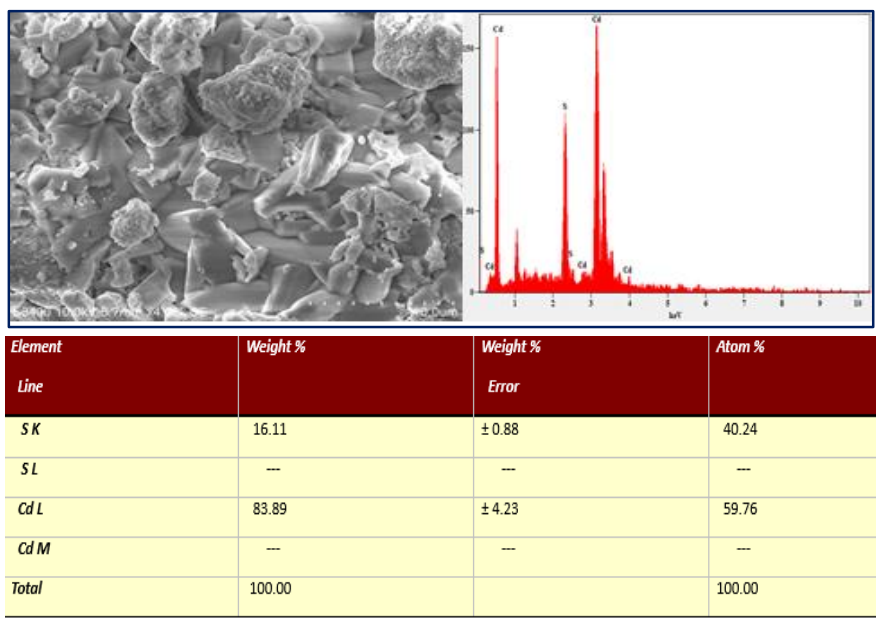

Fig. 4 SEM and EDAX images of electrochemically synthesized CdS nanoparticles

\subsection{Photodegradation Kinetics and COD Measurements}

\subsubsection{Effect of Concentration of Carboxylic Acids}

The photodegradation experiment were carried out by taking four different concentrations of carboxylic acid solutions $\left(0.5 \times 10^{-3}\right.$ to $3 \times 10^{-3}$ $\mathrm{N})$ and keeping constant weight of CdS nanoparticles. The change in concentration of the carboxylic acids was recorded by appearance of pink colour by using $\mathrm{NaOH}$ solution by volumetric method. A plot of $\log \mathrm{V} / \mathrm{V}_{0}$ versus time was linear up to $60 \%$ of the reaction illustrate the disappearance of carboxylic acid follows $1^{\text {st }}$ order kinetics (Fig. 5). The rate constant values are given in Table 1 and rate of the reaction decreased when increase the acid solution. The logic beyond that is with the increase of acid concentration, the solution becomes more intense and the path length of the photons entering the solution and the rate of the reaction is decreased and the few photons reached the catalyst surface. Hence the production of hydroxyl radicals is reduced. Therefore, the photodegradation efficiency has reduced. To account for the mineralization of acids solution COD values were investigated at different stages (Fig. 6). The formation of different radical species during photodegradation is predicted as below reaction route ways.

$$
\begin{array}{ll}
\mathrm{e}^{-} \mathrm{cb}+\mathrm{O}_{2} & \rightarrow \mathrm{O}_{2}^{-} \\
\mathrm{H}^{+}{ }_{\mathrm{vb}}+\mathrm{H}_{2} \mathrm{O} & \rightarrow \mathrm{H}^{+}+{ }^{\circ} \mathrm{OH} \\
\mathrm{O}_{2}^{-}+\mathrm{H}^{+} & \rightarrow \mathrm{HO}^{-} \\
\mathrm{HO}_{2}^{-}+\mathrm{e}^{-} \mathrm{cb}+\mathrm{H}^{+} & \rightarrow \mathrm{H}_{2} \mathrm{O}_{2} \\
\mathrm{H}_{2} \mathrm{O}_{2}+\mathrm{O}_{2}^{-} & \rightarrow-\mathrm{OH}+\mathrm{OH}^{-}+\mathrm{O}_{2} \\
\cdot \mathrm{OH}+\text { carboxylic acid } & \rightarrow \mathrm{CO}_{2}+\mathrm{H}_{2} \mathrm{O}+\text { Simple inorganic salts }
\end{array}
$$

The carboxylic acid solution was found to have mineralized into $\mathrm{H}_{2} \mathrm{O}$, $\mathrm{CO}_{2}$ and simpler inorganic salts [27]. The photodegradation efficiency of the photo catalyst was calculated by the equation,

Photodegradation Efficiency = (Initial COD - Final COD $) \times 100 /$ Initial COD 
Table 1 Effect of photodegradation at different concentration of carboxylic acids under UV light

\begin{tabular}{|c|c|c|c|c|c|}
\hline $\begin{array}{l}\text { Catalyst } \\
0.02 \mathrm{~g}\end{array}$ & $\begin{array}{l}\text { Carboxylic } \\
\text { acids }\end{array}$ & $\begin{array}{l}\text { Conc. of } \\
\text { acids in } \\
10^{-3}(\mathrm{~N})\end{array}$ & $\begin{array}{l}\mathrm{k} \\
10^{-3} \\
\sec ^{-1}\end{array}$ & $\begin{array}{l}\text { Time taken for } \\
95 \% \text { Degradation } \\
\text { in } \mathrm{min}\end{array}$ & $\begin{array}{l}\text { Photodegradation } \\
\text { Efficiency \% }\end{array}$ \\
\hline \multirow{9}{*}{ 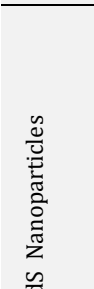 } & \multirow[t]{4}{*}{$\mathrm{Cl}_{3} \mathrm{CCOOH}$} & 0.5 & 4.91 & 10 & 96.87 \\
\hline & & 1.0 & 4.60 & 40 & 98.38 \\
\hline & & 2.0 & 0.51 & 220 & 97.36 \\
\hline & & 3.0 & 0.21 & 360 & 98.76 \\
\hline & \multirow[t]{4}{*}{$\mathrm{ClCH}_{2} \mathrm{COOH}$} & 0.5 & 2.46 & 30 & 92.30 \\
\hline & & 1.0 & 1.58 & 60 & 97.72 \\
\hline & & 2.0 & 0.32 & 260 & 94.11 \\
\hline & & 3.0 & 0.19 & 390 & 96.77 \\
\hline & \multirow[t]{4}{*}{$\mathrm{CH}_{3} \mathrm{COOH}$} & 0.5 & 2.22 & 50 & 86.36 \\
\hline \multirow{3}{*}{ 己ु } & & 1.0 & 0.96 & 90 & 97.05 \\
\hline & & 2.0 & 0.24 & 290 & 94.59 \\
\hline & & 3.0 & 0.16 & 410 & 95.23 \\
\hline
\end{tabular}
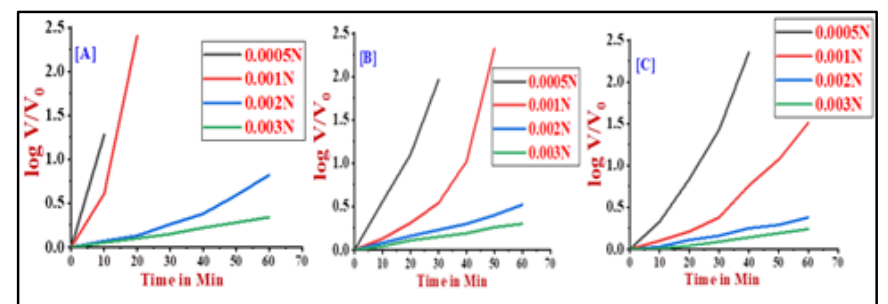

Fig. 5 Effect of concentration of carboxylic acids on the rate of degradation under UV light [A] $\mathrm{Cl}_{3} \mathrm{CCOOH}[\mathrm{B}] \mathrm{ClCH}_{2} \mathrm{COOH}$ and [C] $\mathrm{CH}_{3} \mathrm{COOH}$

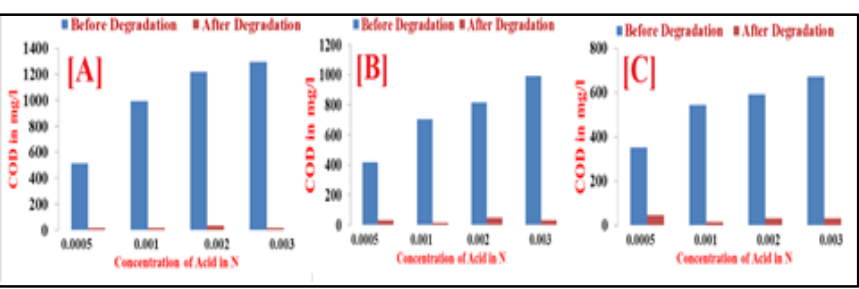

Fig. 6 Effect of concentration of carboxylic acid on COD values under UV light $[\mathrm{A}]$ $\mathrm{Cl}_{3} \mathrm{CCOOH}[\mathrm{B}] \mathrm{ClCH}_{2} \mathrm{COOH}$ and $[\mathrm{C}] \mathrm{CH}_{3} \mathrm{COOH}$

\subsubsection{Effect of Catalyst Loading}

To investigate the effect of catalyst loading the experiment were carried out at five different amounts of catalyst by varying $0.002 \mathrm{~g}$ to $0.03 \mathrm{~g}$ keeping acid concentration constant. The study showed that when increase the catalyst from 0.002 to $0.03 \mathrm{~g}$ increased the efficiency of degradation.

Further when increase the catalyst above $0.02 \mathrm{~g}$ photoactivity of the catalyst is decreased, due to aggregation of CdS nanoparticles at higher concentration causing a decrease in the number of active sites on catalyst surface and increase in the light scattering of CdS nanoparticles at high concentration [28]. This tends to decrease the passage of light through the sample. Further, the present study indicated, from economic point of view, the optimized photocatalyst loading is $0.02 \mathrm{~g} / 20 \mathrm{~mL}$ (Figs. 7 and 8 ; and Table 2).

Table 2 Effect of catalyst loading on the photodegradation of carboxylic acids under UV light

\begin{tabular}{lllll}
\hline $\begin{array}{l}\text { Carboxylic } \\
\text { acids }\end{array}$ & $\begin{array}{l}\text { CdS } \\
\text { Nanoparticles }\end{array}$ & $\begin{array}{l}\mathrm{k} \\
10^{-3} \mathrm{sec}^{-1}\end{array}$ & $\begin{array}{l}\text { Time taken for } \\
95 \% \text { degradation } \\
\text { in min }\end{array}$ & $\begin{array}{l}\text { Photodegradation } \\
\text { Efficiency } \%\end{array}$ \\
\hline $\mathrm{Cl}_{3} \mathrm{CCOOH}$ & $0.002 \mathrm{~g}$ & 0.36 & 240 & 96.77 \\
$1.0 \times 10^{-3}$ & $0.005 \mathrm{~g}$ & 0.62 & 180 & 98.38 \\
& $0.01 \mathrm{~g}$ & 0.89 & 120 & 95.16 \\
& $0.02 \mathrm{~g}$ & 4.60 & 40 & 98.38 \\
& $0.03 \mathrm{~g}$ & 1.65 & 60 & 98.38 \\
$\mathrm{ClCH}_{2} \mathrm{COOH}$ & $0.002 \mathrm{~g}$ & 0.20 & 270 & 93.18 \\
$1.0 \times 10^{-3}$ & $0.005 \mathrm{~g}$ & 0.36 & 240 & 97.72 \\
& $0.01 \mathrm{~g}$ & 0.86 & 140 & 95.23 \\
& $0.02 \mathrm{~g}$ & 1.58 & 60 & 97.72 \\
& $0.03 \mathrm{~g}$ & 1.12 & 80 & 97.72 \\
$\mathrm{CH}_{3} \mathrm{COOH}$ & $0.002 \mathrm{~g}$ & 0.13 & 320 & 91.17 \\
$1.0 \times 10^{-3}$ & $0.005 \mathrm{~g}$ & 0.26 & 270 & 94.11 \\
& $0.01 \mathrm{~g}$ & 0.66 & 130 & 97.05 \\
& $0.02 \mathrm{~g}$ & 0.96 & 90 & 97.05 \\
& $0.03 \mathrm{~g}$ & 0.61 & 110 & 94.11 \\
\hline
\end{tabular}

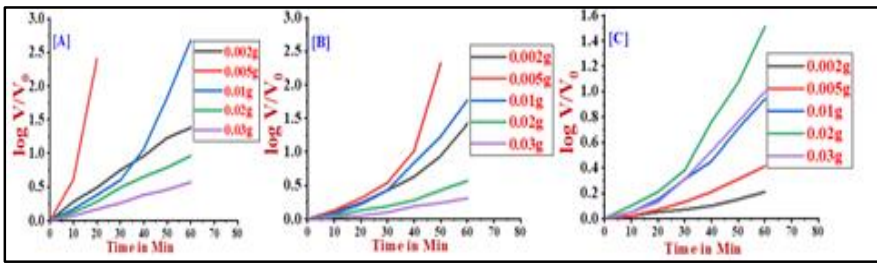

Fig. 7 Effect of catalyst loading on the rate of degradation of carboxylic acids under UV light [A] $\mathrm{Cl}_{3} \mathrm{CCOOH}[\mathrm{B}] \mathrm{ClCH}_{2} \mathrm{COOH}[\mathrm{C}] \mathrm{CH}_{3} \mathrm{COOH}$

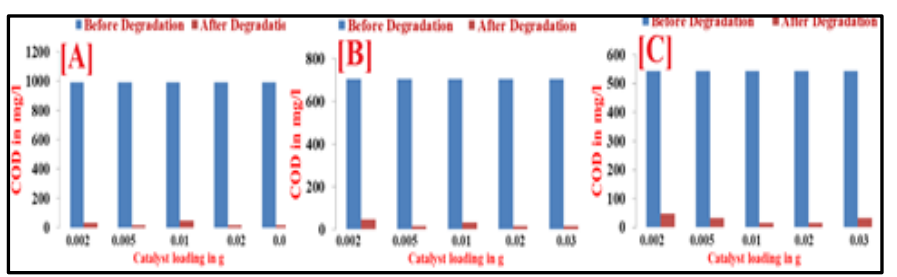

Fig. 8 Effect of catalyst loading of carb oxylic acids on COD values under UV light [A] $\mathrm{Cl}_{3} \mathrm{CCOOH}[\mathrm{B}] \mathrm{ClCH}_{2} \mathrm{COOH}[\mathrm{C}] \mathrm{CH}_{3} \mathrm{COOH}$

\subsubsection{Effect of Temperature}

Temperature is one of the essential factors which effect the rate of photodegradation. To examine the effect of temperature, the experiment was carried out at three different temperatures. It is confirmed that when temperature is increased the degradation efficiency of acid is increased, and observed that the rate of degradation is not very significant at low temperature. However, the reaction is more significantly influenced at high temperature since the diffusion rate increased with temperature. An increase of temperature could bring about an increase in the degradation rate [29]. The rate constant and COD values are reported in (Table 3 and Figs. 9 and 10). The thermodynamic parameters were calculated and are reported in Table 4.

Table 3 Effect of temperature on the photodegradation of carb oxylic acids under UV light

\begin{tabular}{|c|c|c|c|c|}
\hline Carboxylic acids & $\begin{array}{l}\text { Catalyst } \\
0.02 \mathrm{~g}\end{array}$ & $\begin{array}{l}\text { Temperature } \\
\text { in } \mathrm{K}\end{array}$ & $\begin{array}{l}\mathrm{k} \\
10^{-3} \mathrm{sec}^{-1}\end{array}$ & $\begin{array}{l}\text { Photodegradation } \\
\text { Efficiency } \%\end{array}$ \\
\hline$\overline{\mathrm{Cl}_{3} \mathrm{CCOOH}}$ & \multirow{9}{*}{ 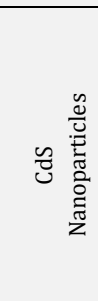 } & 293 & 1.09 & 97.99 \\
\hline \multirow[t]{2}{*}{$1.0 \times 10^{-3}$} & & 298 & 4.52 & 97.99 \\
\hline & & 308 & 6.93 & 96.77 \\
\hline $\mathrm{ClCH}_{2} \mathrm{COOH}$ & & 293 & 0.58 & 93.18 \\
\hline \multirow[t]{3}{*}{$1.0 \times 10^{-3}$} & & 298 & 1.58 & 97.72 \\
\hline & & 308 & 2.73 & 95.45 \\
\hline & & 293 & 0.38 & 97.05 \\
\hline $\mathrm{CH}_{3} \mathrm{COOH}$ & & 298 & 0.94 & 97.05 \\
\hline $1.0 \times 10^{-3}$ & & 308 & 1.72 & 94.11 \\
\hline
\end{tabular}

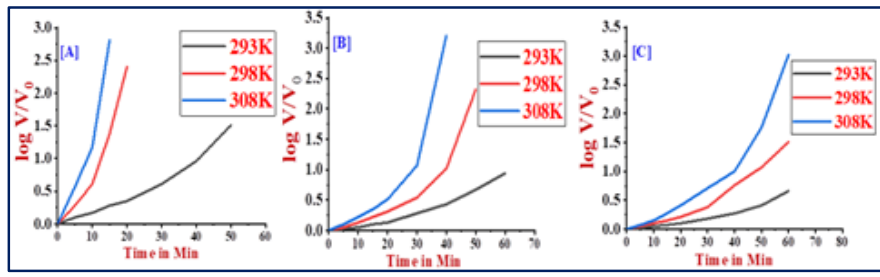

Fig. 9 Effect of temperature on the rate of degradation of carboxylic acids under UV light $[\mathrm{A}] \mathrm{Cl}_{3} \mathrm{CCOOH}[\mathrm{B}] \mathrm{Cl}_{3} \mathrm{CCOOH}[\mathrm{C}] \mathrm{CH}_{3} \mathrm{COOH}$

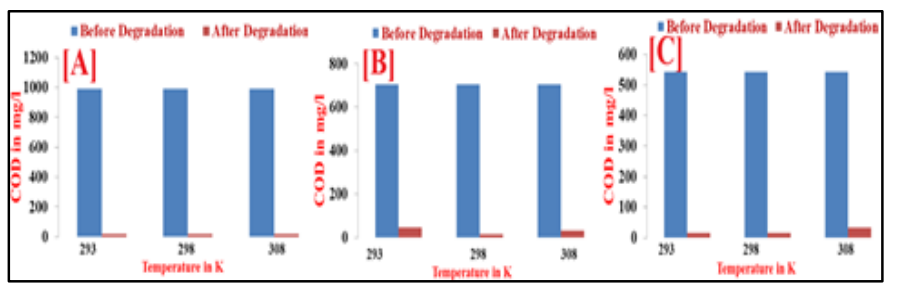

Fig. 10 Effect of temperature of carboxylic acids on COD values under UV light [A] $\mathrm{Cl}_{3} \mathrm{CCOOH}[\mathrm{B}] \mathrm{Cl}_{3} \mathrm{CCOOH}[\mathrm{C}] \mathrm{CH}_{3} \mathrm{COOH}$

Table 4 Thermodynamic parameters for carboxylic acids at $298 \mathrm{~K}$

\begin{tabular}{lllll}
\hline Carboxylic acids & $\begin{array}{l}\Delta \mathrm{H}^{\#} \\
\mathrm{KJmol}^{-1}\end{array}$ & $\begin{array}{l}\Delta \mathrm{S}^{\#} \\
\mathrm{JK}^{-1} \mathrm{~mol}^{-1}\end{array}$ & $\begin{array}{l}\Delta \mathrm{G}^{\#} \\
\mathrm{KJmol}^{-1}\end{array}$ & $\begin{array}{l}\mathrm{Ea} \\
\mathrm{kcal} / \mathrm{mol}\end{array}$ \\
\hline $\mathrm{Cl}_{3} \mathrm{CCOOH}$ & 32.15 & -182.48 & 87.64 & 8.28 \\
$\mathrm{Cl}_{3} \mathrm{CCOOH}$ & 54.90 & -113.70 & 89.80 & 13.72 \\
$\mathrm{CH}_{3} \mathrm{COOH}$ & 64.49 & -88.39 & 90.98 & 16.01 \\
\hline
\end{tabular}




\subsection{Linear Free Energy Relation (LFER)}

Structural modification of a reactant molecule may influence the rate or equilibrium constant of a reaction through polar, steric and resonance effects. Out of a number of empirical models for the description of relationships between structures and reactivity the most successful and intensively used are the liner free energy relationships. The experiments were made to arrive at a linear free energy relation for the oxidation/Photodegradation of carboxylic acids by using CdS nanoparticles. Testing of Taft equation was obtained for plot of $\log k$ vs $\sigma^{*}$. The following regression equation was obtained.

$$
\log k=0.290 \sigma^{*}-3.07(\mathrm{r}=0.993)
$$

The positive value of polar constant $\rho^{*}$ although small, it indicates that electron donating capacity decreases. The rate of oxidation /degradation of carboxylic acids by using CdS nano particles decrease in the order: trichloroacetic acid $>$ chloroacetic acid $>$ acetic acid.

The activation energy value is highest for the slowest reaction and viceversa, indicating that the reaction is enthalpy controlled. The activation enthalpies $\left(\Delta \mathrm{H}^{\#}\right)$ and entropies $\left(\Delta \mathrm{S}^{\#}\right)$ for the degradation of carboxylic acids through oxidation are linearly related. From the slope of the plot of $\Delta \mathrm{H}^{\#}$ vs $\Delta \mathrm{S}^{\#}(\mathrm{r}=0.993)$, the isokinetic temperature $(\beta)$ was calculated and it is found to be $344 \mathrm{~K}$. This is further verified by employing the Exner criterion [30] with a plot of $\log _{1} 298 \mathrm{~K}$ vs $\operatorname{logk}_{2} 308 \mathrm{~K}$ which is linear. From the Exner's slope, $\beta$ was calculated by using expression $\beta=\mathrm{T}_{2} \mathrm{~T}_{1}$ (b1) $/\left(\mathrm{bT}_{2}-\mathrm{T}_{1}\right)$ [31] where, $\mathrm{k}_{1}$ and $\mathrm{k}_{2}$ are the rate constants at the temperature $\mathrm{T}_{2}$ and $\mathrm{T}_{1}$ respectively and $\mathrm{T}_{2}>\mathrm{T}_{1}, \mathrm{~b}$ is the slope of $\operatorname{logk}_{2}$ against $\log \mathrm{k}_{1}$ and it is found to be $355 \mathrm{~K}$ (Fig. 11).

The value of $\beta$ is higher than the temperature range employed in the present work, supporting the fact that the oxidation of carboxylic acids is enthalpy controlled. The fairly high negative values of entropy of activation point towards the formation of fairly rigid activated state. The constancy of $\Delta \mathrm{G}^{\#}$ values indicates that the carboxylic acids undergo oxidation/ degradation via an identical mechanism [32].

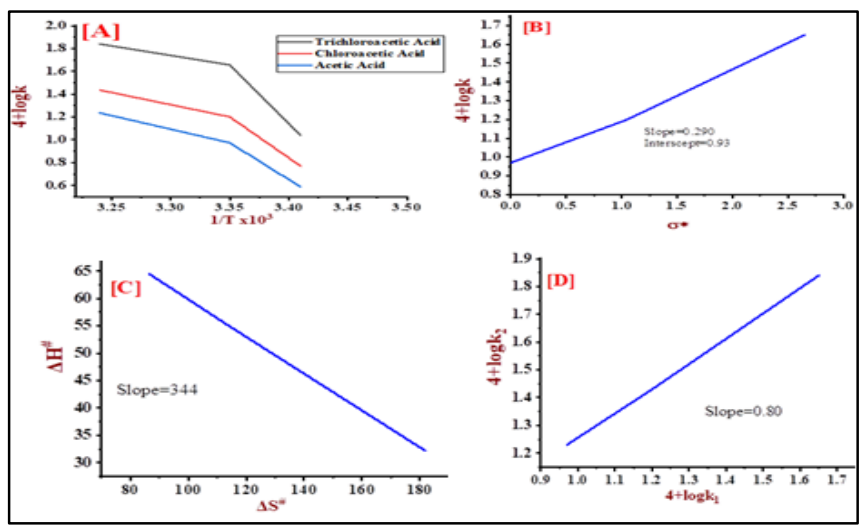

Fig. 11 (a) Arrhenius plot for carboxylic acids (b) Taft plot LFER for carboxylic acids (c) isokinetic temperature relationship for carboxylic acids (d) Exner criterion for carboxylic acids

\subsubsection{Effect of Light Intensity}

The photodegradation rate constant is compared with UV light and sunlight. It is perceived that the photodegradation rate constant is increased in UV light compared to sunlight for synthesized CdS nanoparticles. The reason beyond that is when a photon interacts on a semiconductor (CdS) energy that overtake the band gap energy of the semiconductor. An electron is jump up from the valence band to the conduction band leaving a hole in the valence band. The excited state conduction band electrons and valence band hole can recombine and dissipate energy in the form of heat and get trapped into the metastable surface states, respectively with electrons acceptors and donors that happened to be adsorbed on the semiconductor surface. The stored energy is dissipated within a few nanoseconds by recombination in the absence of suitable $\mathrm{e}^{-} / \mathrm{h}^{+}$scavengers. If a suitable scavenger is available to trap the electron recombination is prevented i.e. subsequent redox reaction may occur. Therefore, the cadmium sulfide nanoparticles act as a very good photocatalyst and is active under UV light compared to sunlight. The rate constant for degradation in sunlight is given in Table 5. It also supports the observed energy band gap $2.39 \mathrm{eV}$ in the UV visible spectral study.

\subsubsection{Degradation in Sunlight}

The comparison of photoactivity with sunlight was carried out. The photocatalytic experiments were carried out by taking $20 \mathrm{~mL}$ of $1.0 \times 10^{-3}$ https://doi.org/10.30799/jnst.294.20060104
$\mathrm{N}$ carboxylic acid solution and $0.02 \mathrm{~g}$ of synthesized CdS nanoparticles in the $50 \mathrm{~mL}$ beaker. All experiments were carried out in an open atmosphere between the times of 9.45 AM to 3.00 PM in the presence of sunlight. It is clear that rate of degradation is very slow in sunlight compare to UV light. Hence the synthesized nanoparticles were active under UV light. The rate constant values were given in Table 5 and Fig. 12.

Table 5 Effect of rate of degradation in sunlight and UV light

\begin{tabular}{llllll}
\hline Catalyst & Concentration & \multicolumn{2}{l}{ Sunlight } & \multicolumn{2}{l}{ UV light } \\
\cline { 3 - 6 } $0.02 \mathrm{~g}$ & $\begin{array}{l}\mathrm{k} \text { carboxylic } \\
\text { acids in }\end{array}$ & $\begin{array}{l}10^{-3} \\
\text { Time taken }\end{array}$ & $\begin{array}{l}\mathrm{k} \\
\text { for 95\% } \\
\text { Degradation }\end{array}$ & $\begin{array}{l}10^{-3} \\
\mathrm{~S}^{-1}\end{array}$ & $\begin{array}{l}\text { Time taken for } \\
\text { in min }\end{array}$ \\
& $0.001 \mathrm{~N}$ & $\mathrm{~S}^{-1}$ & & $\begin{array}{l}\text { Degradation in } \\
\text { min }\end{array}$ \\
\hline $\mathrm{CdS} \mathrm{NPs}$ & $\mathrm{Cl}_{3} \mathrm{CCOOH}$ & 0.88 & 130 & 4.60 & 40 \\
& $\mathrm{Cl}_{3} \mathrm{CCOOH}$ & 0.48 & 180 & 1.58 & 60 \\
& $\mathrm{CH}_{3} \mathrm{COOH}$ & 0.34 & 210 & 0.96 & 90 \\
\hline
\end{tabular}

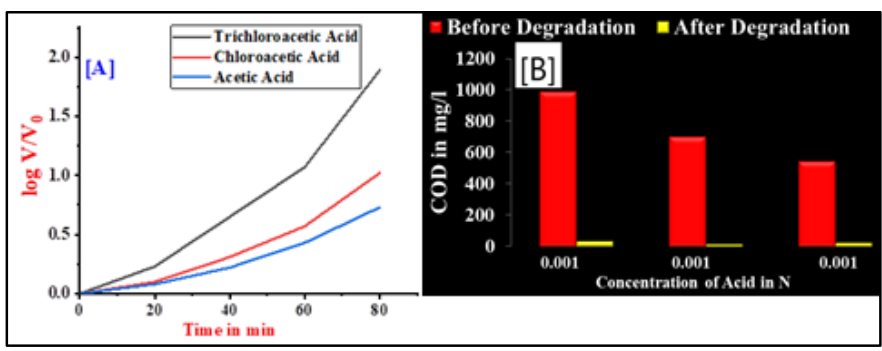

Fig. 12 [A] Effect of concentration of carboxylic acids on the rate of degradation and [B] COD values under sunlight

\subsubsection{Reuse of Catalyst}

The reuse of catalyst was investigated to see the efficiency of photodegradation of the carboxylic acid solutions. After complete degradation of acid solution, the degraded acid solution was kept outside for $9 \mathrm{~h}$ without exposing the UV-light and supernatant liquid sample was decanted. The catalyst was thoroughly washed with double distilled water and reuse for the photodegradation by taking new acid solutions. The reuse of photocatalyst shown almost same degradation efficiency compared to the fresh sample. This can be recommended the photocatalyst can be regenerated and reused.

\subsection{Antibacterial Assay}

The antibacterial activity of CdS nanoparticles were studied by using gram positive (Bacillus subtilis MTCC 2763) and gram negative (Escherichia coli MTCC 40) bacteria by disc diffusion Kirby-Bauer method in Mueller Hinton Agar Plate by determining the ZOI. All reference bacterial strains were obtained from Microbial Typing Culture Collection (MTCC), Chandigarh, India.

\subsubsection{Antimicrobial Activity - Disc Diffusion Method}

To test disc diffusion assay, $20 \mathrm{~mL}$ of sterilized and molten Mueller Hinton Agar media was poured in to the sterilized petri plates. The reference bacterial strains were cultured overnight at $37{ }^{\circ} \mathrm{C}$ in Mueller Hinton broth and adjusted to a final density of $10^{7} \mathrm{CFU} / \mathrm{mL}$ by 0.5 McFarland standards. $100 \mu \mathrm{L}$ of the pathogenic bacteria cultures were transferred onto plate and made culture lawn. The comparative stability of discs containing Gentamycin was made. CdS nanoparticles were loaded into $6 \mathrm{~mm}$ sterile discs and placed on the culture plates and incubated at $37^{\circ} \mathrm{C}$ for 24 hours.

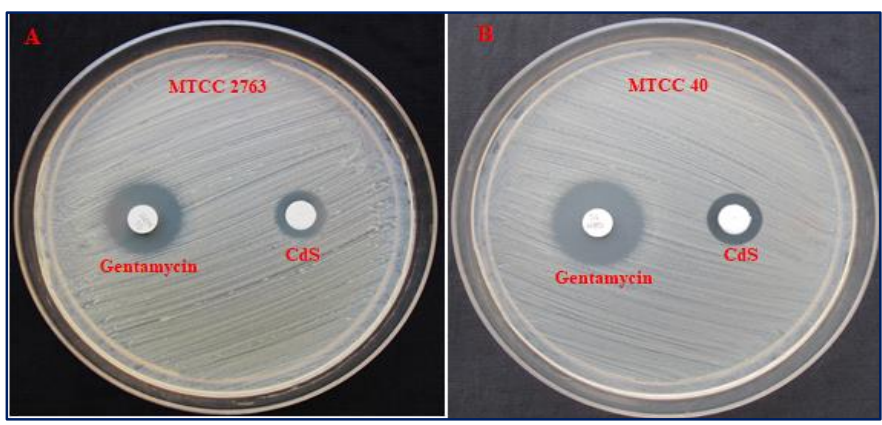

Fig. 13 Zone of inhibition against (A) Bacillus subtilis and (B) Escherichia coli bacteria

By measuring the diameter of the ZOI formed around the disc, the antibacterial efficacy of CdS nanoparticles was determined. All assays 
were performed in triplicates. The observed ZOI for CdS nanoparticles are 11.05 and $13.41 \mathrm{~mm}$ against Bacillus subtilis and Escherichia coli respectively which is mentionedd in Table 6. From this zone measurement it could be stated that $\mathrm{CdS}$ nanocomposite possesses effective antibacterial property. It was also interesting to note that, the samples had antibacterial activity against both gram positive and gram-negative bacterial culture. Therefore, it could be concluded that the creation of active species by photo induced reaction are the main source towards the bacterial toxicity, in the case of transition metal oxide compounds. CdS particles inhibited bacterial growth which was found from the clear inhibition zone (a concentration of $10 \mu \mathrm{g} / \mathrm{mL}$ ). The diameter of inhibition zones (in millimeters) around the compound against test strain are shown in Fig. 13 and Table 6.

Table 6 Antibacterial effect of CdS nanoparticles by zone of inhibition (mm) against test strains

\begin{tabular}{lll}
\hline Test Bacteria & $\begin{array}{l}\text { CdS } \\
\text { nanoparticles }\end{array}$ & $\begin{array}{l}\text { Positive control } \\
\text { gentamycin }(10 \mu \mathrm{g})\end{array}$ \\
\hline Bacillus subtilis MTCC 2763 & $11.05 \pm 0.10$ & $20.08 \pm 0.05$ \\
Escherichia coli MTCC 40 & $13.41 \pm 0.19$ & $22.15 \pm 0.13$ \\
\hline
\end{tabular}

\section{Conclusion}

In the present work, the CdS nanoparticles were synthesized by electrochemical method. The photocatalytic study for the synthesized CdS nanoparticles were investigated by the kinetics of photodegradation of carboxylic acids using volumetric method against $\mathrm{NaOH}$ solution. Photodegradation kinetics of carboxylic acids recommended that the dematerialize of acids follows $1^{\text {st }}$ order kinetics. The photodegradation rate is low in sunlight when compare to UV light. Hence it could be concluded that the synthesized CdS nanoparticles acts as a very good photocatalyst and is active under UV light. The complete degradation of acid solution was confirmed by COD measurement. The COD values revealed that $96 \%$ of the acid had been degraded. The synthesized nanoparticles show appreciably good inactivation against the strains Bacillus subtilis and Escherichia coli.

\section{Acknowledgement}

Authors are grateful to UGC-BSR (No.F.18-1/2011/1621072 (BSR), IOE, UPE, CPEPA, DST-PURSE and university of Mysore for their support to carry out this project.

\section{References}

[1] Sowbhagya, Sannaiah Ananda, Synthesis and characterization of Se-doped ZnO nanoparticles by electrochemical method: Photodegradation kinetics of indigo carmine dye and study of antimicrobial, antimitotic activities of Se-doped ZnO nanoparticles, Am. Chem. Sci. J. 4(5) (2014) 616-637.

[2] W.P. McConnell, J.P. Novak, L.C. Brousseau, R.R. Fuierer, R.C. Tenent, D.L.J. Feldheim, Electronic and optical properties of chemically modified metal nanoparticles and molecularly bridged nanoparticle arrays, Phys. Chem. B. 104 (2000) 8925-8930

[3] C. Liu, Z.J. Zhang, Size-dependent super paramagnetic properties of Mn spinel ferrite nanoparticles synthesized from reverse micelles, J. Chem. Mater. 13 (2001) 2092-2096.

[4] H.C. Charan Kumar, Rajegowda Shilpa, Sanniaha Ananda, Synthesis of cadmium oxide nanoparticles by electrochemical method: Its photodegradative effects on carboxylic acids and antibacterial behaviours, J. Nanosci. Tech. 5(5) (2019) 840-845.

[5] A.S. Aldwayyan, F.M. Al-Jekhedab, M. Al-Noaimi, B. Hammouti, T.B. Hadda, et al., Synthesis and characterization of $\mathrm{CdO}$ nanoparticles starting from organometalic dmphen-CdI 2 complex, Int. J. Electrochem. Sci. 8 (2013) 1050610514

[6] Y.J. Yang, Z.L.Y. He, H. Xiang, Electrochemical synthesis of free-standing CdS nanoparticles in ethylene glycol, Rus. Elektrokhim. 42(9) (2006) 1060-1064
[7] J.L. Delplancke, J. Dille, J. Reisse, G.J. Long, A. Mohan, F. Grandjean, Magnetic nanopowders: Ultrasound-assisted electrochemical preparation and properties, Chem. Mater. 12 (2000) 946-952.

[8] H.Y. Ma, B.S. Yin, S.Y. Wang, Y.L. Jiao, W. Pan, et al., Synthesis of silver and gold nanoparticles by a novel electrochemical method, J. Chem. Phys. Chem. 5 (2004) 68-75.

[9] Raziyeh Akbarzadeh, Seyede Sara Khalili, Hossein Dehghani, Fabrication and study of optical and electrochemical properties of CdS nanoparticles and the GO-CdS nanocomposite, New J. Chem. 40 (2016) 3528-3535.

[10] J.L. Zhao, J.A. Bardecker, A.M. Munro, M.S. Liu, Y.H. Niu, et al., Efficient CdSe/CdS quantum dot light-emitting diodes using a thermally polymerized hole transport layer, Nano Lett. 6 (2006) 463-467.

[11] Hassan Karami, Ahmad Kaboli, Pulsed current electrochemical synthesis of cadmium sulfide nanofibers, Int. J. Electrochem. Sci. 5 (2010) 706-719.

[12] T. Hirai, S. Shiojiri, Komasawa, Preparation of metal sulfide composite ultrafine particles in reverse micellar systems and their photocatalytic property, .J Chem. Eng. Jpn. 27 (1994) 590-597.

[13] Yunxia Hu, Baoyuan Wang, Jieqiong Zhang, Tian Wang, Rong Liu, et al., Synthesis and photoelectrochemical response of CdS quantum dot-sensitized $\mathrm{TiO}_{2}$ nanorod array photoelectrodes, Nanoscale Res. Lett. 8(222) (2013) 1-5.

[14] Hole Saroj Shankar, Deepak Dhote, Meena Vidhale, A facile route for preparation of CdS nanoparticles, Sci. Rev. Chem. Commun. 2(3) (2012) 427 431.

[15] S. Muruganandam, G. Anbalagan, G. Murugadoss, Optical, electrochemical and thermal properties of co-doped CdS nanoparticles using polyvinylpyrrolidone, Appl. Nanosci. 5 (2015) 245-253.

[16] Y.K. Liu, J.A. Zapien, C.Y. Geng, Y.Y. Shan, C.S. Lee, et al., High-quality CdS nanoribbons with lasing cavity, Appl. Phys. Lett. 85 (2004) 3241-3243.

[17] L.E. Brus, Electronic wave functions in semiconductor clusters: experiment and theory, J. Phys. Chem. 90 (1986) 2555-2560.

[18] C.Z. Yao, B.H. Wei, L.X. Men, H. Li, Q.J. Gong, et al., Controllable electrochemical synthesis and photov oltaic performance of $\mathrm{ZnO} / \mathrm{CdS}$ core-shell nanorod arrays on fluorine-doped tin oxide, J. Power Sour. 207 (2012) 222-228.

[19] G. Chaitanya Lakshmi, S. Ananda, Somashekar, C. Ranganathaiah, Synthesis of $\mathrm{ZnO} / \mathrm{ZrO}_{2}$ nanocomposites by electrochemical method and photocatalytic degradation of Fast green dye, paper dyeing and printing press effluent, Int. J. Adv. Mater. Sci. 3 (2012) 221-237.

[20] K. Byrappa, A.K. Subramani, S. Ananda, K.M.L. Rai, R. Dinesh, M. Yoshimura, Photocatalytic degradation of rhodamine B dye using hydrothermally synthesized ZnO, Bull. Mater. Sci. 29 (2006) 1-6.

[21] Subhash Kondawar, Ritu Mahore, Ajay Dahegaonkar, Shikha Agrawal, Electrical conductivity of cadmium oxide nanoparticles embedded polyaniline nanocomposites, Adv. Appl. Sci. Res. 2(4) (2011) 401-406.

[22] X.Y. Ma, G.X. Lu, B.J. Yang, Study of the luminescene characteristics of cadmium sulfide quantum dots in a sulponic group polyaniline (SPAn) film, Appl. Surf. Sci. 187 (2002) 235-238.

[23] X.R. Ye, C. Daraio, C. Wang, J.B. Talbot, Room temperature solvent-free synthesis of monodisperse magnetite nanocrystals, J. Nanosci. Nanotech. 6(3) (2006) 852-856.

[24] T.P. Sharma, D. Patidar, N.S. Saxena, K. Sharma, Measurement of structural and optical band gaps of $\mathrm{Cd}_{1-\mathrm{x}} \mathrm{Zn}_{\mathrm{x}} \mathrm{S}(\mathrm{x}=4$ and 6$)$ nanomaterials, Ind. J. Pure Appl. Phys. 44 (2006) 520-615

[25] B. cullity, Elements of X-ray diffraction, A.W.R.C Inc, Massachusctts,1967.

[26] B. Srinivasa Rao, B. Rajesh Kumar, Preparation and characterization of CdS nanoparticles by chemical co-precipitation technique, 8(3) (2011) 177-185

[27] Rakesh, Sannaiah Ananda, Netkal M. Made Gowda, Kithanakere Ramesh Raksha, Synthesis of niobium doped $\mathrm{ZnO}$ nanoparticles by electrochemical method: characterization, photodegradation of indigo carmine dye and antibacterial study, Adv. Nanopart. 3 (2014) 133-147.

[28] K.R. Raksha, Sannaiah Ananda, An investigation on kinetics of photocatalysis, electrical property and biological activity of electrochemically synthesized ZnS and Ru: ZnS nano photocatalysts, J. Applicab. Chem. 3(1) (2014) 397-412.

[29] B. Kraeutler, A.J. Bard, Heterogeneous photocatalytic decomposition of saturated carboxylic acids on $\mathrm{TiO}_{2}$ powder decarboxylative route to alkanes, J. Am. Chem. Soc. 100 (1978) 5985-5992.

[30] O. Exner, On the enthalpy-entropy-relationship, Coll. Czech Chem. Commun. 29 (1964) 1094-1113.

[31] O. Exner, Correlation analysis in chemistry, Plenum Press, London, 1978.

[32] Bott, Garry, Leslie D. Field, Sever Sternhell, Steric effects. A study of a rationally designed system, J. Am. Chem. Soc. 102(17) (1980) 5618-5626.

[33] K. Thonguriwong, P. Amornpitaksuk, S. Suwanboon, Photocatalytic and antibacterial of $\mathrm{Ag}$ doped $\mathrm{ZnO}$ thin fims prepared by sol-gel dip coating method, J. Sol gel Sci.Technol. 62 (2012) 304-312.

[34] K. Tam, Antibacterial activity of $\mathrm{ZnO}$ nanoroads prepared by hydrothermal method, Thin solid Films 516 (2008) 6167-6174.

[35] S. Shrivastava, T. Bera, A. Roy, G. Singh, P. Ramachandra Rao, D. Dash Characterization of enhanced antibacterial effects of novel silver nanoparticles, Nanotech, 8 (2007) 225103-225110. 